\section{Public Health Genomics}

Public Health Genomics 2010;13:1-12

DOI: $10.1159 / 000206346$
Received: July 3, 2008

Accepted after revision: December 17, 2008

Published online: March 2, 2009

\title{
Will Knowledge of Gene-Based Colorectal Cancer Disease Risk Influence Quality of Life and Screening Behavior?
}

\author{
Findings from a Population-Based Study
}

\author{
Scott Ramsey ${ }^{\mathrm{a}}$ David Blough $^{\mathrm{b}}$ Cara McDermott ${ }^{\mathrm{a}}$ Lauren Clarke \\ Robin Bennett ${ }^{c}$ Wylie Burke ${ }^{c, d}$ Polly Newcomb ${ }^{a}$ \\ ${ }^{\mathrm{a}}$ Fred Hutchinson Cancer Research Center, and ${ }^{\mathrm{b}}$ Department of Pharmacy, ${ }^{\mathrm{C}}$ Division of Medical Genetics, \\ and ${ }^{\mathrm{d}}$ Department of Medical History and Ethics, University of Washington, Seattle, Wash.; ${ }^{\mathrm{e}}$ Cornerstone Systems \\ Northwest Incorporated, Lynden, Wash., USA
}

\section{Key Words}

Cancer • Polymorphism • Quality of life $\cdot$ Gene variant

testing $\cdot$ Screening behavior

\begin{abstract}
Background: Several gene variants conveying a modestly increased risk for disease have been described for colorectal cancer. Patient acceptance of gene variant testing in clinical practice is not known. We evaluated the potential impact of hypothetical colorectal-cancer-associated gene variant testing on quality of life, health habits and cancer screening behavior. Methods: First-degree relatives of colorectal cancer patients and controls from the Seattle Colorectal Cancer Familial Registry were invited to participate in a web-based survey regarding testing for gene variants associated with colorectal cancer risk. Results: 310 relatives and 170 controls completed the questionnaire. Quality of life for the hypothetical carrier state was modestly and nonsignificantly lower than current health after adjustment for sociodemographic and health factors. In the positive test scenario, 30\% of respondents expressed willingness to change their diet,
\end{abstract}

$25 \%$ to increase exercise, and $43 \%$ to start colorectal cancer screening. The proportions willing to modify these habits did not differ between groups. Conclusions: Testing for gene variants associated with colorectal cancer risk may not influence quality of life, but may impact health habits and screening adherence. Changing behaviors as a result of testing may help to reduce cancer incidence and mortality, particularly among those at higher risk for colorectal cancer.

Copyright $\odot 2009$ S. Karger AG, Basel

\section{Introduction}

Colorectal cancer is the third most common cancer and the third leading cause of cancer mortality in the USA [1]. Approximately $10-15 \%$ of individuals with colorectal cancer have an affected family member, and a small fraction of these individuals have cancer family syndromes with known mutations [2]. For the rest, a combination of environmental and genetic factors plays a role in the development of the colorectal cancer [3].

\section{KARGER \\ Fax +4161306 1234 \\ E-Mail karger@karger.ch}

www.karger.com
(C) 2009 S. Karger AG, Basel

1662-4246/10/0131-0001\$26.00/0

Accessible online at:

www.karger.com/phg
Scott D. Ramsey

Fred Hutchinson Cancer Research Center

1100 Fairview Avenue North M3-B232

Seattle, WA 98109 (USA)

Tel. +1 206667 7846, Fax +1 206667 5977, E-Mail sramsey@fhcrc.org 
A number of studies have identified high-prevalence, low-penetrance gene variants (polymorphisms, haplotypes) that appear to be associated with a somewhat higher risk of developing colorectal cancer [4-7]. Although persons are not currently tested for these variants in clinical practice, the prospect of using genetic and environmental information to tailor screening and modify environmental exposures as a means of prevention is a conceptual cornerstone of personalized medicine as applied to cancer $[8,9]$. A test for these gene variants would differ in an important way from the cancer susceptibility tests currently in clinical use, such as BRCA [10] and Lynch syndrome testing [11]: rather than identifying rare persons with very high lifetime risk, the gene variant test would predict a moderate but clinically meaningful increase in cancer risk among as many as $10-15 \%$ of the population. As a result, the test could be considered for population screening.

We conducted a population-based survey to determine how a hypothetical test for gene variants associated with a moderately increased colorectal cancer risk might influence individuals' health-related quality of life (HRQOL), cancer worry, health habits, and screening behavior. In addition, to determine whether an individual's family history of colorectal cancer (and thus his/her current estimate of cancer risk) modified these issues, we compared participants without colorectal cancer who did or did not have a family history of colorectal cancer.

Our first hypothesis was that an individual's perceived quality of life would fall after being informed that he or she carried a cancer-associated gene variant. We also hypothesized that being told one is a carrier would have a greater impact on perceived HRQOL for persons with experience in caring for a family member with cancer than for those who had no such experience. Finally, we postulated that relatives of colorectal cancer patients would be more likely to modify their behavior - specifically their diet, exercise habits, and adherence to colorectal cancer screening recommendations - in response to information about their risk status as determined by testing for moderate-risk genetic variants than those who have no family history of colorectal cancer.

\section{Subjects and Methods}

\section{Population Sample}

Study participants were recruited from the Seattle Colorectal Cancer Family Registry (C-CFR) to participate in this survey concerning HRQOL and the behavioral impact of genetic testing for high-prevalence, low-penetrance gene variants. The C-CFR is a consortium of 6 international sites supported by the National Cancer Institute, initiated in 1997, dedicated to the establishment of a comprehensive collaborative infrastructure for interdisciplinary studies in the genetics and genetic epidemiology of colorectal cancer [12]. The cooperating institutions collect epidemiological information and laboratory specimens from affected families and relatives at all risk levels for colorectal cancer. The Seattle C-CFR ascertains incident colorectal cancer cases from the Seattle metropolitan area through the Western Washington Surveillance, Epidemiology, and End Results (SEER) program. All individuals ages 18-74 diagnosed with colorectal cancer in the Western Washington SEER region (except in situ cases) were invited to enroll in the C-CFR. First-degree relatives of these cancer patients (parents, siblings and children) were then contacted to participate in the registry. Finally, for each first-degree relative of the enrolled cases, the C-CFR identified a control participant without a family history of colorectal cancer, selected from Washington State Department of Licensing (DOL) records. These DOL controls were then matched to the first-degree relatives based on age and sex. The C-CFR database of cancer cases, first-degree relatives, and DOL controls are re-contacted periodically to assess cancer incidence and vital status.

\section{Theoretical Model}

Theoretical models of health behavior suggest that perceptions of risk, seriousness, and control are factors that influence the adoption of health-related behaviors [13-15]. Applying these models to the domain of genetic susceptibility for cancer, researchers have shown that these factors are important for persons carrying high-risk mutations such as the BRCA1/2 and HNPCC mutations [16-19]. In the area of genetic testing, theoretical models suggest that emotional factors such as cancer worry can motivate action such as preventive maneuvers to mitigate perceived risk [20-22]. However, empirical studies suggest that extreme distress, as might be experienced by some individuals carrying genetic mutations that place them at very high risk for cancer, may result in passive coping and avoidance of health-improving strategies such as screening [23-26]. It is less clear how perceptions regarding the level of risk might influence cancer worry and health behaviors, particularly for persons whose cancer risk is only modestly higher than the general population's such as those with a single affected family member. This issue is particularly salient to the area of polymorphism testing.

\section{Sampling and Survey Procedures}

Drawing from the C-CFR population, first-degree relatives of colorectal cancer patients (hereafter referred to as 'relatives') and those without a family history of colorectal cancer (hereafter referred to as 'controls') were invited to participate in the survey as described above. To reflect a possible range of age where gene variant screening might begin, relatives and controls between the ages of 20 and 65 from the C-CFR population were invited to participate in the survey $(n=2,160)$. All persons in this age group were invited except relatives with family histories that were consistent with Lynch syndrome or adenomatous polyposis coli $(\mathrm{n}=$ 234).

Relatives and controls were mailed an invitation letter that included a description of the study, security and confidentiality materials, and instructions for accessing a study-specific web site (using a unique log-in and password) that contained further in- 
formation about the study and the survey itself. The mailing also included a response card with a self-addressed stamped envelope. Individuals could decline to participate either through the study web site or by returning the card after checking the 'decline to participate' box. The letter stated that a study coordinator would call the recipient to inquire about interest and to answer questions if the participant did not complete the survey, return the response card, or contact the study office within 3 weeks.

In past studies, we have found that follow-up phone calls greatly improve participation and reduce errors in completing quality-of-life surveys [27]. The study coordinator called potential participants if they did not respond to the initial mailing within 3 weeks' time. During the phone call, the study coordinator described the method of completing the survey (i.e. via the Internet), and offered options for completing the survey to those who did not have a computer or internet access at home (e.g. public library). Those who declined to participate during the telephone call were thanked and not contacted further.

\section{Survey Content}

The survey was administered and completed on a study-dedicated secure website. Prior to the question portion of the survey, participants were given information on colorectal cancer, including risk factors, screening modalities, recommended screening schedules, and the likely relationship between genes and risk for colorectal disease, including the difference between modest risk posed by the gene variants in the hypothetical test and higher risk for individuals with highly penetrant mutations such as those associated with Lynch syndrome. Specifically, persons were told that in the general population, the lifetime risk for developing colorectal cancer is $4 \%$, and that carrying a polymorphism that raised the risk by $50 \%$ would mean a person's lifetime risk would be $6 \%$.

In the first section of the survey, participants completed demographic questions, the EQ-5D, family history questions, a question asking them to estimate their risk for developing colorectal cancer, colorectal cancer screening history questions, lifestyle and diet questions, and a visual analogue scale (VAS) for rating their current HRQOL on a scale of $0-100$. The EQ-5D is a standardized instrument for use as a measure of HRQOL. Applicable to a wide range of health conditions and treatments, it provides a simple descriptive profile and a single index value for health status, ranging from 0 to 1 [28]. Because family experience with cancer can influence both perceptions of cancer risk and screening behavior [29-32], respondents were also asked whether they have cared for a family member with any type of cancer, and if so, the extent of their involvement in that family member's cancer treatment.

Participants also completed an interactive version of the standard gamble interview [33]. The standard gamble is a method of assigning utilities for a given health state. Utilities are a measure of an individual's preference for a particular health state, reflecting perceived HRQOL in that state. The health state may be one the individual has experienced or an imagined state based on a description provided by the interviewer. Details describing the theory and methods of the standard gamble are available in reference texts and manuscripts [34, 35]. Briefly, the respondent is asked to choose one of two options: (1) a chronic health state that would continue indefinitely, and (2) a gamble that results in one of two outcomes, a certain amount of life in ideal health or im- mediate painless death. The probability of immediate death in the gamble is varied systematically until the respondent is indifferent between the certain health state and the gamble. The risk of immediate death in the gamble at the point of indifference is then translated to a utility score, which can range from 0 (death) to 1 (ideal health). In this survey, the chronic health state of interest was one where the respondent had knowledge that he or she carried a gene variant that was associated with an increased risk for colorectal cancer. Respondents were also asked to rate their current 'chronic' health. For both the gene variant and the participant's current health, patients were presented with a choice of remaining in that health state or selecting a gamble between ideal health and immediate death.

In the second section of the survey the participant was presented with a hypothetical scenario stating that his or her doctor ordered a blood test for a polymorphism that provided information about his or her risk for colorectal cancer. Participants were asked to rate their own risk for developing colorectal cancer and then were told to imagine a polymorphism test that raised their risk by $50 \%$. The numerical implications of a $50 \%$ higher risk on their baseline estimate were presented to them. After describing this test and what the results would mean, they were asked to consider two possible outcomes: (1) the results indicated they were a polymorphism carrier, and (2) the results indicated they were not a carrier. There were separate questions following each possible outcome asking the respondent whether - after knowing the results of the test - he or she would change diet, exercise habits, and (for those who were eligible for screening by age) colorectal cancer screening behaviors. Participants were also asked about whether knowing the result of the test (positive and negative) would influence their overall cancer worry.

Participants were able to log in and out of the password-protected website, thus allowing them to complete the survey as their schedules permitted them to do so. Participants also had access to a contact area on a sidebar of the web display, which allowed them to send questions or comments via e-mail to the study coordinator. Additionally, the web site and the invitation letter included contact information for assistance by mail, telephone, or e-mail from the study coordinator. The study coordinator responded to patient queries by telephone or e-mail within $24 \mathrm{~h}$ during weekdays.

If participants did not answer a particular question, the survey automatically directed the participant to that question with a prompt to complete the question. If a participant wanted to refuse to answer a question, he or she was directed to choose the option 'I prefer not to answer the question' and then continue. All participant responses and survey activity were recorded on a secure server in real time and transmitted to the study coordinator.

We used registry information that was available for the C-CFR sample population to identify respondent characteristics that predicted survey nonresponse (either active refusal or failure to complete the survey) after excluding those who were deemed ineligible as the result of illness or other factors leading to inability to complete the survey. Factors in the logistic regression model $(1=$ nonresponse) included age, sex, race, marital status, urban versus rural residence, educational attainment, and whether the individual was from the relative or control group. Race as defined by the participant was previously gathered by the C-CFR survey.

Because HRQOL data are typically highly skewed, we used nonparametric tests to evaluate the unadjusted data stratified by 
respondent group. We calculated average utility weights for each health state (current health, carrier of gene variant) for the entire sample, then stratifying by risk group (relative or control). We compared standard gamble utility weights, EQ-5D summary scores, and VAS ratings for relatives versus persons with no family history using the Wilcoxon two-sample test. The standard gamble utility measure compared the current health and 'gene variant' states for the relative and control groups.

Spearman's test was used to evaluate the correlation between an individual's assessment of his or her lifetime cancer risk and (1) being a relative or a control and (2) receipt of colorectal cancer screening within recommended time frame.

Generalized linear models were used to determine whether patient factors modified the effects of the hypothetical gene variant carrier status on health state utilities, cancer worry, health habits, and intentions towards screening compared to reported levels prior to the gene variant testing scenario. The dependent variables for each of the regression models were as follows:

(1) health state utilities - this variable included both the participant's utility value for current health and for the gene variant carrier state, derived from the standard gamble;

(2) cancer worry in response to gene variant test result (positive test: -2 to 0 with $-2=$ very worried, $0=$ no worry; negative test: -2 to $2,-2$ = very worried, $2=$ very relieved);

(3) health habits: participant's stated degree of change reported in exercise to test results (positive test: exercise $0-2$ with $0=$ no change, 2 = 'exercise a lot more'; negative test: -1 to 2 ; -1 = 'exercise less', 2 = 'exercise a lot more') and diet in response to being told of a positive or negative gene test scenario (positive and negative test: diet $0-2$ with $0=$ no changes, $2=$ big changes);

(4) colorectal cancer screening intent as a result of the test ( 0 = 'no, I don't get screened and wouldn't plan to change now'; $1=$ 'yes, I don't get screened as often as recommended and would see my doctor about screening' or 'I have never been screened and would see my doctor about screening').

Independent variables for all models included age, gender, race (white or nonwhite), lower education status (high school or less), marital status, relative versus control, accompanying a family member through cancer treatment or speaking frequently with him or her during treatment (yes/no).

\section{Results}

We mailed invitations to 1,294 relatives and 866 controls. A total of 397 (18.4\%) study participants were not reached despite the initial mailing and 5 follow-up phone calls. Of those who were successfully contacted, 947 (43.8\%) declined participation via the self-addressed postcard or at the follow-up phone call. An additional 336 (15.6\%) respondents were deemed ineligible after contact by the study coordinator for one of two reasons: (1) the individual was unable or unwilling to access the internet; (2) the respondent had a severe illness that prevented completion of the survey. After answering the family history questions, 20 people in the control group revealed a family history of colorectal cancer which was unknown at the time of their initial C-CFR interview and were thus re-categorized as relatives. After reassigning those 20 participants to the relative category, as they now had a family history of colorectal cancer, a total of 310/1,314 (23.6\%) relatives and 170/846 (20.1\%) controls completed the survey.

We conducted a logistic regression of all relatives and controls to examine factors associated with nonresponse. We first excluded those who were found to be ineligible after approach. Among eligible participants, male sex and African American race (vs. white) were significantly associated with survey nonresponse. College and graduate school education was associated with higher likelihoods of survey response.

Tables 1 and 2 list demographic characteristics, health behaviors, and HRQOL responses of the respondents, stratified by whether they were a relative or a control. Compared to controls, female relatives were significantly younger, less highly educated, and reported a significantly higher average number of relatives with colorectal cancer and any cancer. The proportion of women was not statistically different in the two groups.

A higher proportion of controls compared to relatives reported either accompanying a family member through treatment for any cancer or speaking frequently with him or her during treatment (table 1). Table 1 also shows individuals' ratings of their current HRQOL, as measured by EQ-5D, VAS, and standard gamble scores. There was no significant difference between relatives and controls on any of these summary measures of health status. There also was no significant difference in diet, alcohol, or tobacco use between groups. Relatives were significantly more likely to have had colorectal cancer screening, but were less likely to exercise regularly. Relatives generally reported a higher estimated lifetime risk of developing colorectal cancer than controls, most notably among persons between the ages of 46 and 55 (estimated lifetime risk: $29 \%$ and $9 \%$, respectively, $\mathrm{p}<0.0001$ ).

Adjusting for participant age, individuals' assessments of their lifetime cancer risk was significantly higher for relatives versus controls and significantly associated with receipt of colorectal cancer screening within the recommended time frame ( $\mathrm{p}<0.0001$ in both instances).

Tables 3 and 4 summarize responses to the hypothetical questions regarding worry/relief, informing friends and family, and intent to modify lifestyle and screening behavior after learning about gene variant carrier status. 
Table 1. Demographics and characteristics of respondents

\begin{tabular}{|c|c|c|c|}
\hline & $\begin{array}{l}\text { No family } \\
\text { history } \\
(\mathrm{n}=170)\end{array}$ & $\begin{array}{l}\text { Relatives } \\
(\mathrm{n}=310)\end{array}$ & $\begin{array}{l}\text { Total } \\
(\mathrm{n}=480)\end{array}$ \\
\hline \multicolumn{4}{|l|}{ Demographics } \\
\hline Male & $67(39)$ & $116(37)$ & $183(38)$ \\
\hline Average age, male & 51.1 & 48.6 & 49.5 \\
\hline Average age, female ${ }^{1}$ & 52.9 & 47.0 & 49.1 \\
\hline \multicolumn{4}{|l|}{ Race } \\
\hline White & $160(94)$ & $288(93)$ & $448(93)$ \\
\hline Nonwhite & $10(6)$ & $22(7)$ & $32(7)$ \\
\hline \multicolumn{4}{|l|}{ Education $^{1}$} \\
\hline Less than high school & $3(2)$ & $1(<1)$ & $4(<1)$ \\
\hline High school graduate & $13(8)$ & $40(13)$ & $53(11)$ \\
\hline Some college or university & $51(30)$ & $119(38)$ & $170(35)$ \\
\hline College graduate or higher & $103(60)$ & $149(47)$ & $252(52)$ \\
\hline Unknown or refused & $0(0)$ & $1(<1)$ & $1(<1)$ \\
\hline \multicolumn{4}{|l|}{ Family history of cancer } \\
\hline Average number of FDR with any cancer other than colorectal ${ }^{1}$ & 0.68 & 1.53 & 1.23 \\
\hline Average number of FDR with colorectal cancer ${ }^{1}$ & 0.00 & 0.96 & 0.62 \\
\hline Average number of SDR with any cancer, including colorectal & 1.54 & 1.75 & 1.68 \\
\hline \multicolumn{4}{|l|}{ Experience with a relative with cancer ${ }^{1}$} \\
\hline Accompanied through diagnosis and treatment & $22(13)$ & $109(35)$ & $131(27)$ \\
\hline Spoke frequently about diagnosis/treatment but did not accompany & $31(18)$ & $100(32)$ & $131(27)$ \\
\hline Spoke occasionally about diagnosis/treatment & $23(13)$ & $61(20)$ & $84(18)$ \\
\hline Spoke very little about diagnosis/treatment & $25(15)$ & $27(9)$ & $52(11)$ \\
\hline Did not speak at all about diagnosis/treatment & $40(24)$ & $11(4)$ & $51(11)$ \\
\hline Refused & $29(17)$ & $2(<1)$ & $31(6)$ \\
\hline \multicolumn{4}{|l|}{ Self assessment of current health } \\
\hline EQ-5D summary score & 0.878 & 0.889 & 0.885 \\
\hline VAS summary score (0-100 scale) & 82.94 & 83.58 & 83.35 \\
\hline \multicolumn{4}{|l|}{ Standard gamble utility score } \\
\hline Women & 0.886 & 0.909 & 0.901 \\
\hline Men & 0.892 & 0.887 & 0.889 \\
\hline All & 0.889 & 0.901 & 0.896 \\
\hline \multicolumn{4}{|l|}{ Estimate of lifetime colorectal cancer risk } \\
\hline Age $<45, \%$ & 13 & 29 & 25 \\
\hline Age $46-55, \%$ & 8 & 29 & 23 \\
\hline Age $56-65, \%$ & 11 & 21 & 16 \\
\hline
\end{tabular}

FDR = First-degree relatives: parents, siblings, children; SDR = second-degree relatives: grandparents, aunts, uncles. Figures in parentheses are percentages.

${ }^{1}$ Significant difference between relatives and controls $(\mathrm{p}<0.05)$.

\section{Positive Test (Carrier) Scenario}

Cancer Worry. Under the scenario of having a cancerassociated gene variant, $69 \%$ of all respondents recorded that they would be 'somewhat' worried by the results; $18 \%$ would be 'very' worried. The proportion who stated they would remain 'very worried' at 1 year following the test was not significantly different from the immediate scenario. There was no significant difference in the percent- age of relatives who reported being 'very worried' at a positive gene variant result compared to controls. Among relatives, there was no relationship between the number of relatives with colorectal cancer and their degree of worry in response to the scenario of having a positive gene variant result $(\mathrm{p}=0.84)$. Among relatives and controls, the level of a participant's involvement with a family member with cancer and their degree of worry in response to the 
Table 2. Self-reported screening and lifestyle behaviors of respondents

\begin{tabular}{|c|c|c|c|}
\hline & $\begin{array}{l}\text { No family history } \\
(\mathrm{n}=170)\end{array}$ & $\begin{array}{l}\text { Relatives } \\
(\mathrm{n}=310)\end{array}$ & $\begin{array}{l}\text { Total } \\
(n=480)\end{array}$ \\
\hline \multicolumn{4}{|c|}{ Screening (persons may list more than one procedure) ${ }^{1}$} \\
\hline FOBT last 2 years & $49(29)$ & $67(22)$ & $116(24)$ \\
\hline Flexible sigmoidoscopy within 5 years & $21(12)$ & $21(7)$ & $42(9)$ \\
\hline Colonoscopy within 5 years & $58(34)$ & $172(55)$ & $230(48)$ \\
\hline No screening & $70(41)$ & $88(28)$ & $158(33)$ \\
\hline \multicolumn{4}{|l|}{ Healthy diet } \\
\hline Healthy diet always & $61(36)$ & $102(33)$ & $163(34)$ \\
\hline Healthy diet sometimes & $106(62)$ & $197(64)$ & $303(63)$ \\
\hline Health diet rarely or never & $1(<1)$ & $10(3)$ & $11(2)$ \\
\hline Refused & $2(1)$ & $1(<1)$ & $3(<1)$ \\
\hline \multicolumn{4}{|l|}{ Exercise habits $^{1}$} \\
\hline Exercise regularly or occasionally & $138(81)$ & $246(79)$ & $384(80)$ \\
\hline Exercise rarely or never & $30(18)$ & $63(20)$ & $93(19)$ \\
\hline Refused & $2(1)$ & $1(<1)$ & $3(<1)$ \\
\hline \multicolumn{4}{|l|}{ Lifestyle habits } \\
\hline Alcohol - drinks less than $1 /$ day & $151(89)$ & $270(87)$ & $421(88)$ \\
\hline Smokes cigarettes, cigars & $11(7)$ & $35(11)$ & $46(10)$ \\
\hline
\end{tabular}

scenario of having a cancer-associated gene variant did show a statistically significant association $(\mathrm{p}=0.008)$ with higher worry for those with greater involvement.

Willingness to Tell Others about Test Results. Overall, nearly $88 \%$ of respondents reported that they would tell their spouse if they had a positive test; approximately three-fourths would tell their siblings. More than 50\% would tell children, parents, or close friends about the results. Less than 3\% said they would tell 'no one' about the result. There was no significant difference between relatives and controls in terms of willingness to tell others about the test result.

Intent to Change Diet, Exercise, and Colorectal Cancer Screening. About $25 \%$ of all participants stated they would exercise 'a lot' more and $30 \%$ would make 'big changes' in their diet. There was no significant difference between relatives and controls in stated intent to change these behaviors. Fifty percent of all participants stated that they already were receiving regular colorectal cancer screening, but significantly more relatives than controls had already had screening $(\mathrm{p}<0.001)$. Among those who did not currently report screening, $43 \%$ stated that they would start. Controls were significantly more likely to state intent to start screening than were relatives $(\mathrm{p}=$ $0.03)$.

\section{Negative Test (Noncarrier) Scenario}

Cancer Worry. Under the scenario of a negative gene variant test, $46 \%$ of all respondents said they would be 'a little relieved'; $33 \%$ said they would be 'very relieved.' There was no significant difference between relatives and controls.

Willingness to Tell Others about the Test Result. As with the positive result, most stated that they would tell their spouse and siblings about a negative test result. Fewer than $50 \%$ would tell their children, parents or close friends. There was no significant difference between relatives and controls in terms of willingness to inform others.

Intent to Change Diet, Exercise, and Colorectal Cancer Screening. Fewer participants indicated that they would make substantial differences in their diet and exercise if the gene variant test came back negative: $60 \%$ would not change their diet and $64 \%$ would not change their exercise. Only $5 \%$ indicated they would exercise 'a lot' more and only $2 \%$ would make 'big changes' in their diet. A smaller proportion of those who were not current regular screeners indicated they would seek screening (26\%) compared to the positive test scenario. There was no difference in responses to the diet, exercise and screening questions for relatives and controls. 
Table 3. Participant responses to questions concerning anxiety/relief, exercise, diet, and screening behavior under a hypothetical scenario where they are told they are a colorectal cancer polymorphism carrier

\begin{tabular}{|c|c|c|c|}
\hline & $\begin{array}{l}\text { No family } \\
\text { history }(\mathrm{n}=170)\end{array}$ & $\begin{array}{l}\text { Relatives } \\
(\mathrm{n}=310)\end{array}$ & $\begin{array}{l}\text { Both } \\
(n=480)\end{array}$ \\
\hline \multicolumn{4}{|l|}{ Feelings of worry } \\
\hline 'Very' worried & $24(14)$ & $61(19)$ & $85(18)$ \\
\hline 'Somewhat' worried & $121(71)$ & $208(67)$ & $329(69)$ \\
\hline No changes & $23(13)$ & $39(13)$ & $62(13)$ \\
\hline Refused & $2(1)$ & $2(<1)$ & $4(<1)$ \\
\hline \multicolumn{4}{|l|}{ Feelings of worry 1 year after results } \\
\hline 'Very' worried & $13(8)$ & $46(15)$ & $59(12)$ \\
\hline 'Somewhat' worried & $121(71)$ & $214(69)$ & $335(70)$ \\
\hline No changes & $33(19)$ & $47(15)$ & $80(17)$ \\
\hline Refused & $3(2)$ & $3(1)$ & $6(1)$ \\
\hline \multicolumn{4}{|l|}{ Informing others about a positive result } \\
\hline Would tell husband/wife/partner about result & $151(89)$ & $269(87)$ & $420(88)$ \\
\hline Would tell siblings about result & $114(67)$ & $240(77)$ & $354(74)$ \\
\hline Would tell children about result & $95(56)$ & $168(54)$ & $263(55)$ \\
\hline Would tell parents about result & $78(46)$ & $187(60)$ & $265(55)$ \\
\hline Would tell close friends about result & $78(46)$ & $169(55)$ & $247(52)$ \\
\hline Would tell acquaintances about result & $18(11)$ & $33(11)$ & $51(11)$ \\
\hline Would tell coworkers about result & $14(8)$ & $43(14)$ & $57(12)$ \\
\hline Would tell no one about result & $4(2)$ & $8(3)$ & $12(3)$ \\
\hline Total people told & 552 & 1,117 & 1,669 \\
\hline Number of people told per respondent & 3.25 & 3.60 & 3.48 \\
\hline Refused & 3 & 2 & 5 \\
\hline \multicolumn{4}{|l|}{ Changes in exercise } \\
\hline Would exercise 'a lot' more & $35(21)$ & $84(27)$ & $119(25)$ \\
\hline Would exercise 'a little' more & $90(53)$ & $162(52)$ & $252(53)$ \\
\hline No changes & $43(25)$ & $62(20)$ & $105(22)$ \\
\hline Exercise less & 0 & 0 & 0 \\
\hline Refused & $2(1)$ & $2(<1)$ & $4(<1)$ \\
\hline \multicolumn{4}{|l|}{ Changes in diet } \\
\hline 'Big' changes & $46(27)$ & $98(32)$ & $144(30)$ \\
\hline 'A few' changes & $110(65)$ & $185(60)$ & $295(62)$ \\
\hline No changes & $12(7)$ & $26(8)$ & $38(8)$ \\
\hline Refused ${ }^{\circ}$ & $2(1)$ & $1(<1)$ & $3(<1)$ \\
\hline \multicolumn{4}{|l|}{ Intentions for colorectal cancer screening 1} \\
\hline Already screen regularly & $73(44)$ & $171(55)$ & $244(51)$ \\
\hline Does not screen, would not change & $4(2)$ & $6(2)$ & $10(2)$ \\
\hline Would start screening/adhere to doctor's recommendation & $85(50)$ & $119(38)$ & $204(43)$ \\
\hline Not sure & $6(3)$ & $13(4)$ & $19(4)$ \\
\hline Refused & $2(1)$ & $1(<1)$ & $3(<1)$ \\
\hline
\end{tabular}

Figures in parentheses are percentages.

${ }^{1}$ Significant difference between relatives and controls $(\mathrm{p}<0.05)$.

Standard Gamble Interview Results: Current Health versus Carrier State

Relatives' and controls' general health state utilities, as measured by the standard gamble, were similar. Both relatives and controls had modestly lower utility scores for the gene variant state compared to current; the dif- ference was significant only for relatives (controls 0.89 vs. $0.88, \mathrm{p}=0.11$; relatives 0.90 vs. $0.88, \mathrm{p}=0.02)$. When standard gamble scores were adjusted for respondent characteristics on multivariate analysis, the gene variant state was not significantly associated with lower utility scores. 
Table 4. Participant responses to questions concerning anxiety/relief, exercise, diet, and screening behavior under a hypothetical scenario where they are told they are a noncarrier of colorectal cancer polymorphism

\begin{tabular}{|c|c|c|c|}
\hline & $\begin{array}{l}\text { No family history } \\
(\mathrm{n}=170)\end{array}$ & $\begin{array}{l}\text { Relatives } \\
(\mathrm{n}=310)\end{array}$ & $\begin{array}{l}\text { Total } \\
(\mathrm{n}=480)\end{array}$ \\
\hline \multicolumn{4}{|l|}{ Feelings of relief or worry } \\
\hline 'Very' worried & $1(<1)$ & 0 & $1(<1)$ \\
\hline 'Somewhat' worried & 0 & $1(<1)$ & $1(<1)$ \\
\hline No changes & $35(21)$ & $63(20)$ & $98(20)$ \\
\hline 'A little' relieved & $76(45)$ & $145(47)$ & $221(46)$ \\
\hline 'Somewhat' or 'very' relieved & $56(33)$ & $100(32)$ & $156(33)$ \\
\hline Refused & $2(1)$ & $1(<1)$ & $3(<1)$ \\
\hline \multicolumn{4}{|l|}{ Informing others about a negative result ${ }^{1}$} \\
\hline Would tell husband/wife/partner & $141(83)$ & $266(86)$ & $407(85)$ \\
\hline Would tell siblings about a result & $90(53)$ & $214(69)$ & $304(63)$ \\
\hline Would tell children about result & $77(45)$ & $153(49)$ & $230(48)$ \\
\hline Would tell parents about result & $63(37)$ & $173(56)$ & $236(49)$ \\
\hline Would tell close friends about result & $59(35)$ & $129(42)$ & $188(39)$ \\
\hline Would tell acquaintances about result & $12(7)$ & $28(9)$ & $40(8)$ \\
\hline Would tell coworkers about result & $7(4)$ & $39(13)$ & $46(10)$ \\
\hline Would tell no one about result & $13(8)$ & $13(4)$ & $26(5)$ \\
\hline Total people told & 462 & 1,015 & 1,477 \\
\hline Number of people told per respondent & 2.72 & 3.27 & 3.10 \\
\hline Refused & 3 & 1 & 4 \\
\hline \multicolumn{4}{|l|}{ Changes in exercise } \\
\hline 'A lot' more & $6(3)$ & $18(6)$ & $24(5)$ \\
\hline 'A little' more & $43(25)$ & $101(33)$ & $144(30)$ \\
\hline No changes & $118(70)$ & $190(61)$ & $308(64)$ \\
\hline Exercise less & 0 & 0 & 0 \\
\hline Refused & $3(2)$ & $1(<1)$ & $4(<1)$ \\
\hline \multicolumn{4}{|l|}{ Changes in diet } \\
\hline 'Big' changes & $2(1)$ & $9(3)$ & $11(2)$ \\
\hline 'A few' changes & $59(35)$ & $121(39)$ & $180(37)$ \\
\hline No changes & $107(63)$ & $179(58)$ & $286(60)$ \\
\hline Refused & $2(1)$ & $1(<1)$ & $3(<1)$ \\
\hline \multicolumn{4}{|l|}{ Intentions for colorectal cancer screening } \\
\hline Already screen regularly & $74(44)$ & $176(57)$ & $250(52)$ \\
\hline Does not screen, would not change & $18(11)$ & $21(7)$ & $39(8)$ \\
\hline Would start screening/adhere to doctor's recommendation & $50(29)$ & $73(23)$ & $123(26)$ \\
\hline Not sure & $26(15)$ & $39(13)$ & $65(14)$ \\
\hline Refused & $2(1)$ & $1(<1)$ & $3(<1)$ \\
\hline
\end{tabular}

Figures in parentheses are percentages.

${ }^{1}$ Significant difference between relatives and controls $(\mathrm{p}<0.05)$.

Respondent Factors Associated with Changes in

Health Habits and Screening following Gene Variant

Testing

Generalized linear models were used to determine whether patient factors modified the effects of the hypothetical gene variant carrier status on overall health state, cancer worry, health habits, and intentions towards screening compared to reported levels prior to the gene variant testing scenario. In the gene variant positive scenario, no single factor was significantly associated with changes in worry, with intentions to change exercise or diet, or with intentions to adhere to screening recommendations. Being told one did not have a cancer-associated gene variant was also not significantly associated with relief or worry, was not significantly associated with intentions to change exercise, diet, or adherence to screen- 
ing recommendations. For each of these models, being a relative of a cancer patient did not influence the significance of the associations.

\section{Discussion}

Drawing from a population-based survey, we conducted interviews to determine how a hypothetical gene variant test for detecting persons with a modestly higher colorectal cancer risk would influence an individual's overall HRQOL, health habits and screening behaviors. In adjusted analysis, a scenario of testing positive did not impact cancer worry or overall quality of life. Most participants said that a positive test result would motivate them to make improvements in their diet and exercise habits. The great majority of those who were eligible but were not receiving regular colorectal cancer screening said that a positive test would motivate them to pursue screening. There was no significant difference in responses among relatives of colorectal cancer patients compared to controls.

Using gene variant testing to identify persons at a modestly higher risk for colorectal cancer has potential benefits compared to family history screening. First, lay persons often have limited knowledge about their risk, and physicians' collection and assessment of family history information is often suboptimal [36-38]. Blood or saliva tests would be simpler to obtain and potentially more accurate than a person's recollection of his or her family history. Further, testing may capture risk status that might not be elicited using standard family history questions.

Second, screening rates for colorectal cancer have been rising, but are still substantially below recommended levels [39]. Screening rates are also suboptimal among people with a family history of colorectal cancer, many of whom are unaware of their increased risk or eligibility for earlier screening [40, 41]. A physician recommendation to screen is a strong predictor of screening in both average risk persons and those with a family history of colorectal cancer, and uptake of screening [42-45]. Gene variant testing could assist physicians to provide tailored screening recommendations. Genetic testing may even be cost effective if the results improved cancer screening rates among those at highest risk for disease [46].

Despite these potential benefits, there are several unresolved issues and potential concerns with population screening to obtain genetic information about cancer risk. The concern we address here is how knowledge of one's genetic status - particularly for relatively common variants that convey a modestly increased risk - would influence health state, cancer worry, and overall quality of life. The issue is important since mass screening gene variant programs would identify far more persons who would be classified as carriers compared to mutation testing, yet far fewer would actually develop disease because of the low penetrance of most variants.

Although several studies have evaluated the impact of testing for rare genetic mutations on quality of life and health-related behaviors $[19,26,47-51]$, to our knowledge this is the first study that has evaluated these issues for gene variants associated with modest disease risks. The results suggest that individuals anticipate that gene variant testing will motivate them to make improvements in their health-related habits and screening. A substantial proportion of respondents noted that the test would create cancer worry, particularly if it was positive. In contrast, the impact on overall quality of life - as measured by the standard gamble survey - was negligible. It is not possible to determine whether this potential contradiction is due to insensitivity in the global measure of HRQOL (utility value) to the test result, or because patient cancer worry following the test result, while real, has little substantive impact on an individual's overall sense of well-being. An important issue for further study is whether DNA-based testing generates more cancer worry than comparable risk information conveyed on the basis of family history.

We note several limitations to this analysis. First, our overall response rate to this internet-based survey was low, and those who did respond were of higher socioeconomic status than the general population or that of the parent study. Although the internet is now nearly ubiquitous, and Washington State ranks fourth in the United States in terms of households with computers (72\%) and home internet access (63\%), access to free or very low-cost internet services outside of the home is still limited (e.g., at public libraries) [52]. Cost and lack of familiarity with computers are relative barriers for persons with low educational attainment and/or low incomes. Thus, although sampling was population based, respondents to this survey do not necessarily represent the overall population makeup of the region.

Second, the scenario was hypothetical. Historically, individuals' response to hypothetical genetic testing scenarios - for example, willingness to be tested - has not corresponded to actual testing experience [53]. Several features of hypothetical case scenarios have been identified as increasing a realistic response, including popula- 
tion-based recruitment, immediacy of the testing scenario, a range of response choices, an accessible and understandable description of testing based on preliminary data, and theory-based content [53]; our testing scenario included all of these features. In addition, our focus on response to test results, rather than interest in testing per se, allowed us to use methodology validated in other studies of health care preferences. Third, the responses to the negative test bias may have been influenced by anchoring bias based on the responses given to the positive test scenario since the latter was presented first to all respondents. Finally, we tailored the response options for worry and exercise based on logical constructs for each scenario, such that certain responses were not available for some health states (e.g., 'very relieved' was not a response option for the gene variant carrier state). If some respondents had wished to respond differently than the available response options, our results would be biased.

It is known that in the case of some mutations with high penetrance, providing people with genetic information on risk may not increase their motivation to change behavior and in some cases may decrease motivation [54]; our data suggesting motivation to change behavior cannot, therefore, be interpreted as predicting behavioral change, but we believe they indicate a potential for utilizing risk knowledge to encourage change, particularly for interventions such as screening that may be affected by physicians' recommendations. Genetic testing in general, and high-prevalence, low-penetrance variants in particular are abstract concepts that may be difficult for lay persons to understand. Our survey was designed and tested for clarity and ease of understanding, yet it is possible that the information was still difficult to grasp for some respondents. One of the advantages of an internet survey is that it allowed us to monitor early on for logic errors in survey responses that would have signaled problems with understanding (e.g., reporting more cancer worry after a negative vs. positive test result). We did not detect such issues with this survey. The method also offered respon- dents the opportunity to stop and ask questions before continuing, perhaps improving the rate of usable responses and avoiding 'respondent questionnaire fatigue.'

Testing for gene variants associated with moderate disease risks is not currently part of standard medical practice. Our survey suggests that a test that is established to have true clinical utility may be accepted by patients, although the impact on feelings of worry is concerning. Furthermore, positive results may motivate beneficial health behaviors, and negative results are not likely to discourage them. Nevertheless, a 'go slow' approach is advisable with implementation of any genetic screening test. Genetic tests for rare mutations such as cancer family syndromes have generally not been shown to substantively affect most people's overall quality of life in the long term, even among those who test positive $[23,26,48,55$, 56]. One reason may be that persons from affected families are usually aware of their increased risk before testing. Patients without family histories would often face a 'surprise' of being told that they are at risk in a scenario of testing for common gene variants, since the prevalence of variants will be high even though the penetrance is lower than mutations. Patients will need to be counseled about the limited implications of a positive test.

If testing of this kind is adopted in clinical practice, research will be needed that informs practitioners about the meaning of the results, how to convey the results, and how to minimize potential misinterpretation of the results by patients. For example, it would be important for health professionals to convey to patients that a negative test result does not necessarily 'negate' a positive family history; that is, screening is still needed.

\section{Acknowledgement}

This work was supported by National Cancer Institute grant R01 CA114794 (S.R.).

\section{References}

Public Health Genomics 2010;13:1-12
1 American Cancer Society: Cancer Facts and Figures stet 2007. Available at: http://www. cancer.org/docroot/stt/content/stt_1x_ Cancer_Facts_Figures_2007.asp. Accessed December 17, 2007.

2 Ramsey SD, Yoon P, Moonesinghe R, et al: Population-based study of the prevalence of family history of cancer: implications for cancer screening and prevention. Genet Med 2006;8:571-575.
-3 Lichtenstein P, Holm NV, Verkasalo PK, et al: Environmental and heritable factors in the causation of cancer - analyses of cohorts of twins from Sweden, Denmark, and Finland. N Engl J Med 2000;343:78-85.

4 Houlston RS, Tomlinson IP: Polymorphisms and colorectal tumor risk. Gastroenterology 2001;121:282-301. 
5 Hubner RA, Houlston RS: MTHFR C677T and colorectal cancer risk: A meta-analysis of 25 populations. Int J Cancer 2007;120: 1027-1035.

6 Chen K, Jiang QT, He HQ: Relationship between metabolic enzyme polymorphism and colorectal cancer. World J Gastroenterol 2005;11:331-335.

$>7$ Kaklamani VG, Hou N, Bian Y, et al: TGFBR ${ }^{*} 6 \mathrm{~A}$ and cancer risk: a meta-analysis of seven case-control studies. J Clin Oncol 2003;21:3236-3243.

8 Collins FS: Shattuck lecture - medical and societal consequences of the Human Genome Project. N Engl J Med 1999;341:2837.

$\checkmark 9$ Collins CD, Purohit S, Podolsky RH, et al: The application of genomic and proteomic technologies in predictive, preventive and personalized medicine. Vascul Pharmacol 2006;45:258-267.

$>10$ US Preventive Services Task Force: Genetic risk assessment and BRCA mutation testing for breast and ovarian cancer susceptibility: recommendation statement. Ann Intern Med 2005;143:355-361.

-11 Lynch HT, Fusaro RM, Lynch JF: Hereditary cancer syndrome diagnosis: molecular genetic clues and cancer control. Future Oncol 2007;3:169-181.

$\checkmark 12$ Newcomb PA, Baron J, Cotterchio M, et al: Colon cancer family registry: an international resource for studies of the genetic epidemiology of colon cancer. Cancer Epidemiol Biomarkers Prev 2007;16:2331-2343.

13 Janz NK, Becker MH: The Health Belief Model: a decade later. Health Educ Q 1984; 11:1-47.

-14 Leventhal H, Diefenbach M, Leventhal E: Illness cognition: using common sense to understand treatment adherence and affect cognition interactions. Cog Ther Res 1992; 16:143-163.

15 Milne S, Sheeran P, Orbell S: Prediction and intervention in health-related behavior: a meta-analytic review of protection motivation theory. J Appl Soc Psychol 2000;30:106143.

16 Audrain J, Schwartz MD, Lerman C, et al: Psychological distress in women seeking genetic counseling for breast-ovarian cancer risk: the contributions of personality and appraisal. Ann Behav Med 1997;19:370-377.

$\checkmark 17$ Croyle RT, Lerman C: Risk communication in genetic testing for cancer susceptibility. J Natl Cancer Inst Monogr 1999;25:59-66.

- 18 Schlich-Bakker KJ, ten Kroode HF, Ausems MG: A literature review of the psychological impact of genetic testing on breast cancer patients. Patient Educ Couns 2006;62:13-20.

19 Broadstock M, Michie S, Marteau T: Psychological consequences of predictive genetic testing: a systematic review. Eur J Hum Genet 2000;8:731-738.
20 Gooding HC, Organista K, Burack J, et al: Genetic susceptibility testing from a stress and coping perspective. Soc Sci Med 2006; 62:1880-1890.

21 Marteau TM, Weinman J: Self-regulation and the behavioural response to DNA risk information: a theoretical analysis and framework for future research. Soc Sci Med 2006;62:1360-1368.

22 Decruyenaere M, Evers-Kiebooms G, Welkenhuysen $\mathrm{M}$, et al: Cognitive representations of breast cancer, emotional distress and preventive health behaviour: a theoretical perspective. Psychooncology 2000; 9:528-536.

23 Gritz ER, Peterson SK, Vernon SW, et al: Psychological impact of genetic testing for hereditary nonpolyposis colorectal cancer. J Clin Oncol 2005;23:1902-1910.

-24 van Oostrom I, Meijers-Heijboer H, Duivenvoorden HJ, et al: The common sense model of self-regulation and psychological adjustment to predictive genetic testing: a prospective study. Psychooncology 2007;16:11211129.

25 Esplen MJ, Madlensky L, Aronson M, et al: Colorectal cancer survivors undergoing genetic testing for hereditary non-polyposis colorectal cancer: motivational factors and psychosocial functioning. Clin Genet 2007; 72:394-401.

26 van Oostrom I, Meijers-Heijboer H, Duivenvoorden HJ, et al: Comparison of individuals opting for BRCA $1 / 2$ or HNPCC genetic susceptibility testing with regard to coping, illness perceptions, illness experiences, family system characteristics and hereditary cancer distress. Patient Educ Couns 2007;65:5868.

27 Ramsey SD, Berry K, Moinpour C, et al: Quality of life in long term survivors of colorectal cancer. Am J Gastroenterol 2002; 97:1228-1234.

28 EuroQol Group: EQ-5D: An instrument to describe and value health. 2007. Available at: http://www.euroqol.org. Accessed November 7, 2008.

29 Palmer RC, Emmons KM, Fletcher RH, et al: Familial risk and colorectal cancer screening health beliefs and attitudes in an insured population. Prev Med 2007;45:336-341.

-30 Coughlin SS, Berkowitz Z, Hawkins NA, et al: Breast and colorectal cancer screening and sources of cancer information among older women in the United States: results from the 2003 Health Information National Trends Survey. Prev Chronic Dis 2007;4: A57.

31 Young WF, McGloin J, Zittleman L, et al: Predictors of colorectal screening in rural Colorado: testing to prevent colon cancer in the high plains research network. J Rural Health 2007;23:238-245.
32 Kinney AY, Hicken B, Simonsen SE, et al: Colorectal cancer surveillance behaviors among members of typical and attenuated FAP families. Am J Gastroenterol 2007;102: 153-162.

33 Center on the Evaluation of Value and Risk in Health: The Cost-Effectiveness Analysis Registry. 2007. Available at: http://www. tufts-nemc.org/cearegistry. Accessed June 23, 2008.

34 Patrick DL, Erickson P: Health Status and Health Policy. New York, Oxford University Press, 1993.

35 Torrance GW: Measurement of health state utilities for economic appraisal. J Health Econ 1986;5:1-30.

-36 Murff HJ, Byrne D, Syngal S: Cancer risk assessment: quality and impact of the family history interview. Am J Prev Med 2004;27: 239-245.

37 Sweet KM, Bradley TL, Westman JA: Identification and referral of families at high risk for cancer susceptibility. J Clin Oncol 2002; 20:528-537.

-38 Tyler CV Jr, Snyder CW: Cancer risk assessment: examining the family physician's role. J Am Board Fam Med 2006;19:468-477.

39 Centers for Disease Control and Prevention: Use of colorectal cancer tests - United States, 2002, 2004, and 2006. Morb Mortal Wkly Rep 2008;57:253-258.

-40 Fletcher RH, Lobb R, Bauer MR, et al: Screening patients with a family history of colorectal cancer. J Gen Intern Med 2007;22:508513.

41 Rees CE, Sheard CE, Echlin K: The relationship between the information-seeking behaviours and information needs of partners of men with prostate cancer: a pilot study. Patient Educ Couns 2003;49:257-261.

42 Beydoun HA, Beydoun MA: Predictors of colorectal cancer screening behaviors among average-risk older adults in the United States. Cancer Causes Control 2008;19:339-359.

43 Sarfaty M, Wender R: How to increase colorectal cancer screening rates in practice. CA Cancer J Clin 2007;57:354-366.

-44 Ferreira MR, Dolan NC, Fitzgibbon ML, et al: Health care provider-directed intervention to increase colorectal cancer screening among veterans: results of a randomized controlled trial. J Clin Oncol 2005;23:15481554.

45 Harewood GC, Wiersema MJ, Melton LJ 3rd: A prospective, controlled assessment of factors influencing acceptance of screening colonoscopy. Am J Gastroenterol 2002;97: 3186-3194.

46 Ramsey SD, Burke W, Pinsky L, et al: Family history assessment to detect increased risk for colorectal cancer: conceptual considerations and a preliminary economic analysis. Cancer Epidemiol Biomarkers Prev 2005; 14 : 2494-2500. 
47 Marteau TM, Croyle RT: The new genetics. Psychological responses to genetic testing. BMJ 1998;316:693-696.

48 Esplen MJ, Madlensky L, Butler K, et al: Motivations and psychosocial impact of genetic testing for HNPCC. Am J Med Genet 2001; 103:9-15.

49 Meiser B, Halliday JL: What is the impact of genetic counselling in women at increased risk of developing hereditary breast cancer? A meta-analytic review. Soc Sci Med 2002; 54:1463-1470.
50 Claes E, Denayer L, Evers-Kiebooms G, et al: Predictive testing for hereditary non-polyp osis colorectal cancer: motivation, illness representations and short-term psychological impact. Patient Educ Couns 2004;55: 265-274.

51 Claes E, Evers-Kiebooms G, Denayer L, et al: Predictive genetic testing for hereditary breast and ovarian cancer: psychological distress and illness representations 1 year following disclosure. J Genet Couns 2005; 14:349-363.

52 US Census Bureau: Computer and Internet Use in the United States. 2005. Available at: http://www.census.gov/prod/2005pubs/ p23-208.pdf. Accessed June 23, 2008.

53 Persky S, Kaphingst KA, Condit CM, et al: Assessing hypothetical scenario methodology in genetic susceptibility testing analog studies: a quantitative review. Genet Med 2007;9:727-738.
54 Marteau TM, Lerman C: Genetic risk and behavioural change. BMJ 2001;322:10561059.

55 Aktan-Collan K, Haukkala A, Mecklin JP, et al: Psychological consequences of predictive genetic testing for hereditary non-polyposis colorectal cancer (HNPCC): a prospective follow-up study. Int J Cancer 2001;93:608611.

56 Schwartz MD, Peshkin BN, Hughes C, et al: Impact of BRCA1/BRCA2 mutation testing on psychologic distress in a clinic-based sample. J Clin Oncol 2002;20:514-520. 